\title{
ИНСТИТУЦИОНАЛЬНЫЕ ФАКТОРЫ РАЗВИТИЯ РОССИЙСКОГО ТЕЛЕКОММУНИКАЦИОННОГО РЫНКА
}

\author{
(c) 2020 Савельев Александр Александрович \\ аспирант, кафедра экономики и менеджмента \\ Московский городской педагогический университет, Россия, Москва \\ E-mail: Alexander@Saveliev.biz
}

Проведён анализ политических, экономических, социальных и технологических факторов, оказывающих влияние на развитие современного российского телекоммуникационного рынка. Определён характер влияния факторов, что позволяет выстроить стратегию дальнейшего развития участников рынка.

Ключевые слова: телекоммуникации, услуги связи, законодательство, конкуренция, $M N P, 3 G, 4 G, 5 G$, PEST-анализ.

Современный телекоммуникационный рынок в Российской Федерации представлен федеральными, мультирегиональными, региональными и локальными операторами подвижной и фиксированной электросвязи, а также так называемыми «виртуальными» операторами, предоставляющими услуги с использованием физической инфраструктуры других операторов (MVNO, агрегаторы каналов) [5, с. 268].

Ключевую долю рынка занимает подвижная связь (>60\%), 16, 12 и 11\% занимают мобильная передача данных, фиксированная передача данных, и фиксированная телефония, соответственно. Более 90\% рынка занимают 5 крупнейших операторов: МТС, МегаФон, Ростелеком, Вымпелком (Билайн) и Теле 2 [1]. Всего Федеральной службой по надзору в сфере связи, информационных технологий и массовых коммуникаций (Роскомнадзор) на сегодняшний день выдано $>6000$ лицензий на оказание услуг связи по передачи данных, за исключением услуг связи по передаче данных для целей передачи голосовой информации, >8000 лицензий на оказание телематических услуг связи, и т.д. [4].

Как и любой современный рынок, телеком подвержен постоянному воздействию различных институциональных факторов макро- и мезосреды, таких как политические институты (законодательные и исполнительные), экономические институты (государственные и рыночные), социальные институты (потребительское сообщество, рынок труда), технологические институты (производственные и информационные).
В России развитие телекоммуникационной отрасли происходит путём преодоления множества трудностей в процессе развития инфраструктуры и обеспечения граждан и предприятий по всей стране необходимыми современными средствами связи. Неотъемлемость телекоммуникационных сервисов в условиях информационного общества обусловливает интерес к рассмотрению факторов, влияющих на развитие рынка услуг связи.

В качестве инструмента для проведения исследования автором настоящей статьи выбран PEST-анализ - инструмент, предназначенный для выявления следующих аспектов макросреды, которые могут повлиять на стратегию: политических (policy), экономических (есоnomy), социальных (society), технологических (technology). [10, c. 36]

Далее рассмотрим несколько факторов для каждой из перечисленных составляющих, проследим их воздействие на участников исследуемого рынка и сформулируем выводы относительно характера влияния соответствующих факторов.

Ключевых политических факторов, влияющих на современный российский телекоммуникационный рынок, можно выделить несколько.

В 2013-м году вступил в силу федеральный закон, обязывающий операторов подвижной связи реализовать услугу переносимости мобильных номеров (Mobile Number Portability, MNP), предоставляющую абоненту право сохранить свой абонентский номер (на безвозмездной или возмездной основе) при заключе- 
нии договора на оказание услуг связи с другим оператором. [2, с. 56] Таким образом, операторы потеряли один из инструментов удержания абонентской базы, ранее абоненты, несмотря на наличие претензий к конкретному оператору, не спешили переходить к конкурентам, поскольку изменение телефонного номера могло привести к потери части контактов. После внедрения MNP операторы прибегают к новым активностям в конкурентной борьбе, таким как разработка индивидуальных тарифных предложений, внедрение дополнительных услуг, постоянный мониторинг и повышение качества абонентского обслуживания и др. Несмотря на то, что внедрение MNP представляло собой сложный и затратный процесс, в целом влияние данного фактора можно оценить как положительное.

Присоединение Крыма к территории России в 2014-м году достаточно быстро привело к тому, что сети сотовой связи украинских операторов на полуострове были выведены из эксплуатации. Дочерние компании российских телекоммуникационных операторов были вынуждены реорганизовать свои крымские филиалы в отдельные юридические лица российской юрисдикции во избежание санкций со стороны западных стран. Позднее некоторые из указанных организаций были реорганизованы путём присоединения к российским операторам связи в качестве структурных подразделений. Данные организационные мероприятия в целом потребовали крупных и срочных инвестиций со стороны бюджетов российских компаний, что привело к отклонению от заданных планов развития бизнеса. С этой точки зрения влияние данного фактора можно оценить как отрицательное в краткосрочной перспективе. Абоненты сетей сотовой связи на территории Крыма были вынуждены менять SIM-карты для получения в пользование российских телефонных номеров. В общероссийском плане телефонной нумерации были выделены новые ёмкости для обслуживания крымских абонентов, что привело к снижению тарифов на звонки, т.к. стала применяться междугородняя тарификация взамен международной. Снижение тарифов на телефонные вызовы было компенсировано ростом трафика между Крымом и регионами РФ. С этой точки зрения влияние данного фактора можно оценить как положительное.

Самым заметным фактором влияния политических институтов на телекоммуникаци- онный рынок за последнее десятилетие можно считать принятие в июле 2016 года двух Федеральных законов (ФЗ) антитеррористической направленности (№ 374-ФЗ и № 375-ФЗ), которые в публичных обсуждениях получили название «закон Яровой» - по фамилии одного из инициаторов процесса рассмотрения и последующего утверждения данных ФЗ. Федеральный закон № 374-Ф3, в числе прочего, выдвигает жёсткие требования к операторам связи в части хранения информации, как служебной, так и пользовательской, транслируемой по сети, в течение 6 месяцев с момента передачи. По оценкам операторов связи и независимых источников, реализация требований, изложенных в Федеральном законе № 374-Ф3, потребует колоссальных инвестиций и трудозатрат. [9, c. 64] Поскольку законопроект не предполагает компенсации затрат операторов на создание и эксплуатацию инфраструктуры, позволяющей хранить гигантские объёмы информации, прогнозируется повышение тарифов на услуги связи для абонентов. Кроме того, внедрение таких технологий потенциально может привести к злоупотреблениям и нарушению частной жизни и тайны связи. В целом влияние данного фактора оценивается как отрицательное.

В качестве примера влияния государственных экономических институтов на развитие телекоммуникационного рынка рассмотрим налоговую политику, проводимую государством в постсоветский период. Желание предпринимателей защититься от притязаний государства на участие в доходах от коммерческой деятельности формирует тенденцию придания бизнесу непрозрачного характера (например, организационные границы фирм, входящих в локальные сообщества, чрезвычайно размыты) и активизации трансфертов активов между фирмами (как если бы они представляли собой одно целое). [3, с. 146] Так, среди региональных операторов фиксированной связи можно найти множество примеров, где одну телекоммуникационную инфраструктуру одновременно эксплуатируют несколько юридических лиц, де-юре не связанных между собой, а де-факто являющихся одной компанией с централизованным управлением, единой штатной структурой, сотрудники которой могут быть официально трудоустроены в разных юридических лицах. Повышение НДС с января 2019 года на 2 процентных пункта привело к пропорциональному (а иногда и непропор- 
циональному) повышению тарифов на услуги связи для абонентов. В целом влияние налоговой политики на развитие рынка можно охарактеризовать как отрицательное.

Рассматривая влияние факторов мезосреды, следует отметить, что одной из ключевых особенностей рынка телекоммуникаций является тот факт, что потребители являются не разовыми покупателями, а постоянными абонентами - подписчиками, использующими услуги на регулярной основе. Данная особенность является причиной уникальной конкурентной политики, сложившейся на рынке: когда ценовая конкуренция теряет свою эффективность, демпинг цен имеет свои экономические пределы, менеджмент компаний делает акцент на иных стратегиях, в т.ч. направленных на повышение качества оказания услуг связи и абонентского обслуживания. [5, с. 269] В условиях тенденции к олигополизации и замедлению темпов развития рынка [7], [8] влияние данного фактора следует считать, безусловно, положительным.

К факторам воздействия социального института на развитие рынка следует отнести взаимодействие операторов связи с потребителями и собственным персоналом.

Принято считать, что мы живём в эпоху информационного общества. Сегодня, как никогда, наблюдается рост потребности человека в получении быстрого и качественного доступа к информационным ресурсам, потребности в оперативной деловой и личной коммуникации, молодое поколение с трудом способно организовать собственный досуг без наличия доступа к средствам связи и информационным технологиям. Потребители предъявляют всё более жёсткие требования к доступности и качеству услуг связи, имеют возможность выбора. Эти требования диктуют необходимость непрерывного технологического, инфраструктурного и маркетингового развития услуг связи, сегодня потребители имеют возможность выбрать поставщика услуг связи не только в крупных городах, но и в провинции. Влияние данного фактора на развитие рынка можно охарактеризовать как положительное.

В условиях экономического кризиса растёт уровень безработицы в стране, что сказывается на отношении населения к работе. В «тяжелые времена» служащие склонны усмирять свои карьерные амбиции, искать пути разрешения рабочих конфликтов, прилагать усилия для профессионального самосовершенствования и достижения наилучших результатов в рамках занимаемой позиции. [6, с. 229] Лояльность персонала позволяет руководству телекоммуникационных компаний проводить грамотную кадровую политику, включать перспективных служащих в кадровый резерв и т.д. Данный социальный фактор можно оценить как позитивный.

В качестве примеров влияния технологических факторов на сети фиксированной электросвязи приведём изобретение и распространение волоконно-оптических кабелей в конце 2000-х годов по настоящее время. Операторы связи быстро оценили экономичность и производительность передачи данных по оптическим каналам по сравнению с медными, что позволило расширить производительность сетей связи и обеспечить потребителей широкополосным доступом к сети Интернет на высоких скоростях передачи данных.

В мобильном секторе телекоммуникаций технологии развиваются более быстрыми темпами. Технологии мобильной связи класси-

Таблиц̧а 1. Поколения мобильной связи

\begin{tabular}{|c|c|c|c|c|c|}
\hline & $1 \mathrm{G}$ & $2 \mathrm{G}$ & $3 G$ & $4 G$ & $5 \mathrm{G}$ \\
\hline Сервисы & Только голос & Голос и текст & $\begin{array}{c}\text { Видеосвязь, } \\
\text { беспровод-ной } \\
\text { Интернет }\end{array}$ & $\begin{array}{c}\text { Высокое каче- } \\
\text { ство воспроизве- } \\
\text { дения голоса, } \\
\text { мультимедиа }\end{array}$ & $\begin{array}{c}\text { Связь в режиме } \\
\text { реального вре- } \\
\text { мени, передача } \\
\text { голограмм }\end{array}$ \\
\hline $\begin{array}{l}\text { Пропускная } \\
\text { способность }\end{array}$ & 10 Кбит/сек & 64 Кбит/сек & 2 Мбит/сек & 1 Гбит/сек & 20 Гбит/сек \\
\hline $\begin{array}{l}\text { Ввод в коммер- } \\
\text { ческую эксплуа- } \\
\text { тацию }\end{array}$ & 1981 & 1991 & 2000 & 2012 & 2020 \\
\hline Технологии & AMPS & $\begin{array}{c}\text { CDMA, } \\
\text { GSM }\end{array}$ & WCDMA & LTE & IMT-2020 \\
\hline
\end{tabular}


фицируются по поколениям в соответствии с технологическими разработками. Поколения определяются как $1 \mathrm{G}-5 \mathrm{G}$, в зависимости от скорости передачи данных, определенной Международным союзом электросвязи (МСЭ). В таблице 1 приведена сводная информация о поколениях технологий мобильной связи.

Согласно классификации МСЭ, в настоящее время мы находимся в эре 4G. [11, с. 12]

В целом влияние института технологий на телекоммуникационный рынок следует оценить, как положительное.

Для определения степени влияния и изменчивости факторов была проведена экспертная оценка с привлечением специалистов по развитию бизнеса и межоператорскому взаимодействию столичных и федеральных операторов связи - Ростелеком, Теле 2, Эр-Телеком Холдинг, Нэт Бай Нэт Холдинг, Старлинк. Степень влияния факторов определена по трёхбалльной шкале, где 1 - влияние фактора мало, 2 - только значительное изменение фактора способно повлиять на развитие рынка, 3 - влияние фактора высоко. Вероятность изменения факторов определена по пятибалльной шкале, где 1 означает минимальную вероятность изменения факто- pa, а 5 - максимальную. Результаты экспертной оценки приведены в таблице 2.

Проведённая оценка факторов показывает, что особое внимание участникам рынка следует уделять политическим и технологическим факторам. Операторы, способные инвестировать ресурсы в проекты по реализации требований законодательства и развитию технологической базы, смогут продолжать развитие на рынке. В противном случае деятельность оператора рискует потерять легитимность или соответствие требованиям современных потребителей, что проведёт к быстрой потере доли рынка и необходимости продажи бизнеса. В зоне риска находятся частные региональные операторы фиксированной связи.

По итогам проведённого анализа можно заключить, что российский телекоммуникационный рынок представляет собой динамичный организм, обеспечивающий эффективную жизнедеятельность современного общества и развивающийся в соответствии с актуальными глобальными тенденциями. Несмотря на наличие негативного воздействия некоторых внешних факторов, развитие не останавливается.

Таблица 2. PEST-анализ российского телекоммуникационного рынка

\begin{tabular}{|c|c|c|c|c|c|c|c|c|}
\hline \multirow{2}{*}{ Описание фактора } & \multirow{2}{*}{$\begin{array}{l}\text { Влияние } \\
\text { фактора }\end{array}$} & \multicolumn{5}{|c|}{ Экспертная оценка } & \multirow{2}{*}{$\begin{array}{c}\text { Средняя } \\
\text { оценка }\end{array}$} & \multirow{2}{*}{$\begin{array}{c}\text { Оценка с } \\
\text { поправкой } \\
\text { на вес }\end{array}$} \\
\hline & & 1 & 2 & 3 & 4 & 5 & & \\
\hline \multicolumn{9}{|l|}{ Политические факторы } \\
\hline $\begin{array}{l}\text { Закон о переносе мобильных номеров } \\
\text { (MNP) }\end{array}$ & 2 & 1 & 2 & 1 & 1 & 1 & 1,2 & 0,14 \\
\hline Присоединение Крыма & 1 & 2 & 3 & 1 & 1 & 1 & 1,6 & 0,01 \\
\hline «Закон Яровой» & 3 & 2 & 3 & 5 & 5 & 4 & 3,8 & 0,67 \\
\hline \multicolumn{9}{|l|}{ Экономические факторы } \\
\hline Повышение НДС & 2 & 1 & 1 & 1 & 2 & 1 & 1,2 & 0,14 \\
\hline $\begin{array}{l}\text { Высокая конкуренция, потребители - } \\
\text { постоянные абоненты }\end{array}$ & 1 & 1 & 1 & 1 & 1 & 1 & 1,0 & 0,06 \\
\hline \multicolumn{9}{|l|}{ Социальные факторы } \\
\hline $\begin{array}{l}\text { Повышенные требования потребителей } \\
\text { к качеству и доступности услуг }\end{array}$ & 2 & 2 & 3 & 3 & 2 & 5 & 3,0 & 0,35 \\
\hline Повышение уровня безработицы & 1 & 1 & 2 & 2 & 4 & 4 & 2,6 & 0,15 \\
\hline \multicolumn{9}{|l|}{ Технологические факторы } \\
\hline Распространение ВОЛС & 3 & 2 & 2 & 2 & 1 & 1 & 2,0 & 0,35 \\
\hline Разработка технологий 5G & 2 & 3 & 3 & 3 & 4 & 5 & 3,6 & 0,42 \\
\hline Итого: & 17 & & & & & & & \\
\hline
\end{tabular}




\section{Библиографический список}

1. Анализ российского рынка телекоммуникационных услуг: итоги 2016 г., прогноз до 2019 г. [Электронный ресурс] / РБК. - 2017.- Электрон. дан.- Режим доступа: https://marketing.rbc.ru/articles/10081/ (дата обращения: 10.11.2019).

2. Бухарев И.А., Плахов В.В. Развитие проекта MNP в Российской федерации // Т-Сотm: Телекоммуникации и транспорт: Том 11. № 1-2017.- С. 52-56.

3. Ломовцева О.А. Институциональные факторы развития сетевых форм организации бизнеса // Вестник ВолгУ. Серия 3: Экономика. Экология. 2005. № 9.- С. 145-149.

4. Реестр лицензий в области связи [Электронный ресурс]/Роскомнадзор - 2019. Электрон. дан. - Режим доступа: https://rkn.gov.ru/communication/register/license/ (дата обращения: 10.11.2019).

5. Савельев A.A. Mystery shopping, CSI\&NPS vs AI: актуальные методы контроля качества клиентского сервиса на российском телекоммуникационном рынке // Гуманитарное образование в экономическом вузе: материалы VII Международной научно-практической очно-заочной конференции. 1-28 ноября 2018 г.- Москва: ФГБОУ ВО «РЭУ им. Г.В. Плеханова», 2019.-С. 268-272.

6. Савельев А.А. PEST-анализ как инструмент определения стратегического развития на примере федерального оператора почтовой связи // Актуальные вопросы экономики, менеджмента и финансов в современных условиях / Сборник научных трудов по итогам международной научно-практической конференции: № 3. Санкт-Петербург - 2016.- С. 226-230.

7. Телеком 2018 [Электронный ресурс] / CNews.- 2018.- Электрон. дан.- Режим доступа: http://www.cnews. ru/reviews/telekom_2018 (дата обращения: 10.11.2019).

8. Телеком 2019 [Электронный ресурс] / CNews.- 2019.- Электрон. дан.- Режим доступа: https://www.cnews. ru/reviews/telekom_2019 (дата обращения: 10.11.2019).

9. Углов И.В. Пути реализации «закона Яровой» в телекоммуникационной отрасли // Т-Сотm: Телекоммуникации и транспорт: № 7-2017.-С. 62-64.

10. Чернышев М.А. Стратегический менеджмент. Основы стратегического - Ростов н/Д: Феникс, 2009. - 506, [1] с.- (Высшее образование).

11. Choi Ch. Predicting customer complaints in mobile telecom industry using machine learning algorithms // A Thesis Submitted to the Faculty of Purdue University In Partial Fulfillment of the Requirements for the degree of Master of Science in Industrial Engineering: School of Industrial Engineering, West Lafayette, Indiana - 2018. - 77 c. 